\title{
The Equine Endometrial Microbiome: A Brief Review
}

\author{
G. Reed Holyoak ${ }^{1 *}$ and Candace C. Lyman² \\ ${ }^{1}$ Department of Veterinary Clinical Sciences, College of Veterinary Medicine, Oklahoma State University, Stillwater, OK, USA \\ ${ }^{2}$ Department of Veterinary Clinical Sciences, College of Veterinary Medicine, Auburn University, Auburn, AL, USA
}

*Corresponding author: G. Reed Holyoak, Department of Veterinary Clinical Sciences, Center for Veterinary Health Sciences, Oklahoma State University, Stillwater, OK, USA.

To Cite This Article: G. Reed Holyoak, Candace C Lyman. The Equine Endometrial Microbiome: A Brief Review. Am J Biomed Sci \& Res. 2021 11(6). AJBSR.MS.ID.001689. DOI: 10.34297/AJBSR.2021.11.001689.

Received: 跙 January 16, 2020; Published: 眥 February 05, 2021

\begin{abstract}
Context
Our purpose is to examine an alternative idea to describing the reproductive tract microbiome in the mare. Defining the reproductive tract microflora in any species including the mare lies in the need to be able to determine the physiologic state of the microbiome in healthy patients in order to develop a deeper understanding of the impact dysbiosis can have on overall health. With the background information we have, and the advancement of sequencing techniques at our disposal it may be time to challenge the veterinary dogma of a "sterile uterus" and adjust our clinical practices accordingly.
\end{abstract}

Keywords: Mare, Paradigm shift, Endometrial microbiota, 16S rDNA

\section{Introduction}

It has been standard dogma that although the vagina is colonized with commensal bacteria, the uterus is maintained as a sterile environment [1] and a failure to eliminate bacteria, sperm and inflammatory products from the uterus post-breeding will result in endometritis and reduced fertility [2]. While relatively more is known about the microbiome of the human reproductive tract, much less is known about the microbial communities residing in the reproductive tract of animals. As with the mare, in cattle it has long been held that bacterial contamination during the periparturient period led to endometritis or metritis in the cow [3]. In all of our farm animal species these dogmata were based on the results from media-based culture systems.

Although culture-based studies have laid out the foundation of our understanding of the uterine microbiota, almost three decades ago there was an indication that culture-based methodologies in identifying microbial populations may underestimate diversity and overestimate the role of culturable bacteria [4]. Focusing on culturable bacteria, often the rarer members of microbial communities, enhances the risk of missing those microbes that are more abundant $[5,6]$. Recently we completed a study in the canine reproductive tract documenting with 16s rDNA-based metagenomics the presence and diversity of both vaginal and uterine microbiomes at the various stages of the estrous cycle, concluding that both the endometrium and the vagina have rich microbial ecosystems [7]. Additionally, a study utilizing cultureindependent $16 \mathrm{~S}$ ribosomal RNA (rRNA) sequencing of the bovine and ovine vaginal microbiota from ectocervicovaginal lavages revealed that cow and ewe vaginal microbiota are unique from previously described vaginal microbial ecosystems [8]. It is clear from these studies that culture-based diagnostic systems miss the great diversity present in both diseased and healthy reproductive tracts and express a need for metagenomic analytics.

We began our metagenomics investigations in the mare to document the underestimation of microbial diversity with common culture methods relative to the presence of microbial DNA using the approach six years ago [9]. This study grew from a study utilizing molecular identification performed by sequencing of PCR products of $16 \mathrm{~S}$ rDNA using $63 \mathrm{~F}$ and $1389 \mathrm{R}$ primers which suggested separate populations of microbiota between the equine uterus and vagina [10]. Differences were shown between vaginal and uterine microbial populations. That while there was a demonstrated transfer of a vaginal subpopulation into the uterus post-breeding there remained distinct differences between the vaginal and endometrial microbiomes [10] However, neither of these studies clearly defined the endometrial microbiota. 
The purpose of describing the reproductive tract microflora in any species including the mare lies in the clinical need to be able to determine the physiologic state of the microbiome in healthy patients in order to develop a deeper understanding of the impact dysbiosis can have on overall health. Understanding the ramifications that broad-spectrum antibiotic use may have on the uterine normal flora should dictate to veterinarians and breeders that treating a breeding mare with antibiotics, in the absence of an understanding of the endometrial microbiome may be counterproductive. With the background information we have and the advancement of sequencing techniques at our disposal it is time to more deeply investigate the dogma of a "sterile uterus" and adjust our clinical practices accordingly if needed [11-16]. The purpose of this review is to discuss what we have learned in our efforts to characterize the equine microbiome in the non-pregnant mare.

The mammalian vagina is known to harbor a rich microbial ecosystem, while the human vaginal microbiome is well-described [17-23], only a few non-human vaginal microbiomes have been described to date $[8,24-26]$. The endometrium on the other hand, was considered a sterile environment $[1,27]$ until a few years ago when that paradigm was challenged by the observation that the human placenta harbors a small but diverse microbiome $[27,28]$. This new view is, however, not without debate [29]. In addition to the human work, a few studies have been performed exploring the microbiome of the bovine and ovine endometrium and placenta [30-33]. While the microbiota of the cow and ewe were similar, the bovine vaginal microbiome showed greater diversity compared to the ovine and both were considerably different from those reported in the human and non-human primates.

Schnobrich, et al. described "Next Generation Sequencing" (MicroGenDX, formally PathoGenius Laboratory, Lubbock, TX) of samples from 10 clinically normal mares and compared those results to traditional methods of diagnosing infectious endometritis [34]. The main problem with the analyses is that the DNA sequences were compared against a bank of known human and equine pathogens, therefore they did not consider all possible normal non-culturable bacteria that have heretofore been undocumented in the normal microbiota of the mare. At the same time a second abstract was presented very similar to one we published in 2011 [9] wherein uterine fluid samples obtained from mares were subjected to metagenomic DNA sequencing of the 16S rRNA gene. These mares were followed around the time of ovulation/artificial insemination $(n=10)$ and during early pregnancy $(n=10)$. The metagenomic sequencing identified over 200 bacterial species in both culture negative and culture positive samples demonstrating as we have that the uterus is not a sterile site at any point during and after estrus. Proteobacteria and Bacteroidetes phyla were statistically associated with culture positive samples according to the Bonferroni correction. Their pilot study strongly correlates with ours in evidencing of the presence of a complex bacterial microbiome of organisms that fails to grow using routine uterine culture methods [35].

Finally, from the same proceedings a third abstract was published describing the Metagenomic analysis of the equine placental microbiome. Fecal, oral, and vaginal samples were taken from pregnant mares within 30 days of foaling, as well as the gravid and non-gravid regions of the chorioallantois at the time of foaling $(\mathrm{n}=4)$. Genomic DNA was isolated from all samples, and the bacterial 16s ribosomal RNA gene was amplified by PCR. Similarly they reported a relative abundance of bacterial species within the chorioallantois. The three phyla represented in the gravid horn were Firmicutes, Proteobacteria, Bacteroidetes, with the same three phyla plus Actinobacteria in the non-gravid horn. The most abundant phyla within the oral, fecal, and vaginal samples Firmicutes and Proteobacteria were also detected in the chorioallantois. The authors noted that the most abundant bacterial phyla in gravid and nongravid chorioallantois share significant overlap, suggesting similar, but not identical, environments within different compartments of the chorioallantois. They also reported that phyla of relatively high abundance in oral and vaginal samples corresponded to those found in the chorioallantois, indicating possible associations between placental and extra-placental microbiota. However, they found significant differences between the gravid horn and the fecal samples [36].

Clearly, this is a fast moving and clinically relevant area of investigation within the field of equine reproductive medicine and health. Further controlled studies are underway in determining the viability of this diagnostic tool in identifying clinical and subclinical cases of infectious endometritis and the role of specific components of the microbiome in the promotion of fertility and maintenance of pregnancy. In this study we have provided the largest and most comprehensive analysis of equine uterine microbiomes to-date and have established the core microbiome of the healthy uterine endometrium. We have also demonstrated that the uterine microbiome of mares raised at deferent geographical locations differ from each other.

\section{Conclusion}

We conclude from our studies and the literature reviewed, that culture-based systems miss the great diversity present in both diseased and healthy reproductive tracts. Given this diversity, there is much to be studied relative to the intra-microbiota interactions and species-intrinsic factors that may be more relevant to the maintaining a state of balance and health and that an imbalance of these factors maybe more important in the development of uterine disease than the abundance of any given bacterial species. 


\section{References}

1. Ansbacher R, Boyson WA, Morris JA (1967) Sterility of the uterine cavity. American Journal of Obstetrics and Gynecology 99(3): 394-396.

2. Troedsson MH (2006) Breeding-induced endometritis in mares. Vet Clin North Am Equine Pract 22(3): 705-712.

3. Dohmen MJ, Joop K, Sturk A, Bols PE, Lohuis JA (2000) Relationship between intra-uterine bacterial contamination, endotoxin levels and the development of endometritis in postpartum cows with dystocia or retained placenta. Theriogenology 54(7): 1019-1032.

4. Whitman WB, Coleman DC, Wiebe WJ (1998) Prokaryotes: the unseen majority. Proc Natl Acad Sci USA 95(12): 6578-6583.

5. Shade A, Hogan CS, Klimowicz AK, Linske M, McManus PS, et al. (2012) Culturing captures members of the soil rare biosphere. Environmental Microbiology 14(9): 2247-2252.

6. Handelsman J (2005) Metagenomics: Application of genomics to uncultured microorganisms. Microbiology and Molecular Biology Reviews 69(1): 195.

7. Lyman CC, Holyoak GR, Meinkoth K, Wieneke X, Chillemi KA, et al (2018) canine endometrial and vaginal microbiomes reveal distinct and complex ecosystems. Forthcoming.

8. Swartz JD, Lachman M, Westveer K, O’Neill T, Geary T, et al. ((2014) Characterization of the Vaginal Microbiota of Ewes and Cows Reveals a Unique Microbiota with Low Levels of Lactobacilli and Near-Neutral pH. Frontiers in veterinary science 1: 19 .

9. Rock KS, Love BC, DeSilva U, Rezabek GB, Meijer WG, et al. (2011) Detectable Differences in the endometrial microbiome between normal and susceptible mares using metagenomic profiling and conventional bacterial culture. Clinical Theriogenology: 3 .

10. Maischberger E (2010) The mucosal barrier function of the equine endometrium [PhD]. Dublin, IRE: University College Dublin.

11. Dezzutti CS, Hendrix CW, Marrazzo JM, Pan Z, Wang L, et al. (2011) Performance of swabs, lavage, and diluents to quantify biomarkers of female genital tract soluble mucosal mediators. PLoS One 6(8): e23136.

12. Dowd SE, Sun Y, Wolcott RD, Domingo A, Carroll JA (2008) Bacterial tag-encoded FLX amplicon pyrosequencing (bTEFAP) for microbiome studies: Bacterial diversity in the ileum of newly weaned Salmonellainfected pigs. Foodborne Pathogens and Disease 5(4): 459-472.

13. Schloss PD, Westcott SL, Ryabin T, Hall JR, Hartmann M, et al. (2009) Introducing mothur: Open-Source, Platform-Independent, CommunitySupported Software for Describing and Comparing Microbial Communities. Applied and Environmental Microbiology 75(23): 7537 7541.

14. Quast C, Pruesse E, Yilmaz P, Gerken J, Schweer T, et al. (2013) The SILVA ribosomal RNA gene database project: improved data processing and web-based tools. Nucleic Acids Research 41(D1): D590-D596.

15. Edgar RC, Haas BJ, Clemente JC, Quince C, Knight R (2011) UCHIME improves sensitivity and speed of chimera detection. Bioinformatics 27(16): 2194-2200.

16. Huson DH, Beier S, Flade I, Gorska A, El-Hadidi M, et al. (2016) MEGAN Community Edition - Interactive Exploration and Analysis of Large-Scale Microbiome Sequencing Data. PLoS Comput Biol 12(6): e1004957.

17. Sirota I, Zarek SM, Segars JH (2014) Potential Influence of the Microbiome on Infertility and Assisted Reproductive Technology. Seminars in Reproductive Medicine 32(1): 35-42.

18. Braundmeier AG, Lenz KM, Inman KS, Chia N, Jeraldo P (2015) WaltherAntonio MRS, et al. Individualized medicine and the microbiome in reproductive tract. Frontiers in Physiology 6.
19. Martin DH, Marrazzo JM (2016) The Vaginal Microbiome: Current Understanding and Future Directions. Journal of Infectious Diseases 214(Supple1): S36-S41.

20.Zhou X, Brown CJ, Abdo Z, Davis CC, Hansmann MA, et al. (2007) Differences in the composition of vaginal microbial communities found in healthy Caucasian and black women. Isme Journal 1(2): 121-133.

21. Srinivasan S, Liu CZ, Mitchell CM, Fiedler TL, Thomas KK, et al. (2010) Temporal Variability of Human Vaginal Bacteria and Relationship with Bacterial Vaginosis Plos One: 5(4).

22. Srinivasan S, Hoffman NG, Morgan MT, Matsen FA, Fiedler TL, et al. (2012) Bacterial Communities in Women with Bacterial Vaginosis: High Resolution Phylogenetic Analyses Reveal Relationships of Microbiota to Clinical Criteria. Plos One 7(6): e37818.

23. Marrazzo JM (2013) Vaginal Biofilms and Bacterial Vaginosis: Of Mice and Women. Journal of Infectious Diseases 207(10): 1481-1483.

24. Barfod KK, Roggenbuck M, Hansen LH, Schjorring S, Larsen ST, et al. (2013) The murine lung microbiome in relation to the intestinal and vaginal bacterial communities. Bmc Microbiology: 13: 303.

25. Yildirim S, Yeoman CJ, Janga SC, Thomas SM, Ho MF, et al. (2014) Primate vaginal microbiomes exhibit species specificity without universal Lactobacillus dominance. Isme Journal 8(12): 2431-2444.

26. Yang X, Yang J, Wang HN, Li CW, He YG, et al. (2016) Normal vaginal bacterial flora of giant pandas (Ailuropoda melanoleuca) and the antimicrobial susceptibility patterns of the isolates. Journal of Zoo and Wildlife Medicine 47(2): 671-675.

27. Giudice LC (2016) Challenging dogma: the endometrium has a microbiome with functional consequences! American Journal of Obstetrics and Gynecology 215(6): 682-683.

28. Aagaard K, Ma J, Antony KM, Ganu R, Petrosino J, et al. (2014) The Placenta Harbors a Unique Microbiome. Science Translational Medicine 6(237): 237ra65

29. Lauder AP, Roche AM, Sherrill-Mix S, Bailey A, Laughlin AL, et al. (2016) et al. Comparison of placenta samples with contamination controls does not provide evidence for a distinct placenta microbiota. Microbiome $4(1): 29$.

30. Santos TMA, Gilbert RO, Bicalho RC (2011) Metagenomic analysis of the uterine bacterial microbiota in healthy and metritic postpartum dairy cows. Journal of Dairy Science 94(1): 291-302.

31. Santos TMA, Bicalho RC (2012) Diversity and Succession of Bacterial Communities in the Uterine Fluid of Postpartum Metritic, Endometritic and Healthy Dairy Cows. Plos One 7(12).

32. Machado V, Oikonomou G, Bicalho M, Knauer W, Gilbert R, et al. (2012) Investigation of postpartum dairy cows' uterine microbial diversity using metagenomic pyrosequencing of the $16 \mathrm{~S}$ rRNA gene. Veterinary Microbiology 159(3-4): 460-469.

33. Peng Y, Wang YH, Hang SQ, Zhu WY (2013) Microbial diversity in uterus of healthy and metritic postpartum Holstein dairy cows. Folia Microbiologica 58(6): 593-600.

34. Schnobrich MR, Atwood K, Barr B, Bradecamp EA, Scoggin CF (2017) Sequencing, culture and cytology results in 10 clinically normal mares. Clinical Theriogenology 9(3).

35. Sathe S, Leiken A, Plummer A (2017) Metagenomic sequencing of the uterine microbial environment during estrus and early pregnancy in mares. Clinical Theriogenology 9(3).

36. Xia YW, Cornelius AJ, Donnelly CG, Bicalho RC, Cheong SH, et al. (2017) Metagenomic analysis of the equine placental microbiome. Clinical Theriogenology 9(3). 